\title{
The Role of Extracellular Matrix in Lung Diseases
}

\author{
Muazzez Derya ${ }^{1}$, Insu Yılmaz ${ }^{2}$ and Metin Aytekin ${ }^{1 *}$
}

${ }^{1}$ Department of Medical Biology, Erciyes University, Faculty of Medicine, Melikgazi 38039, Kayseri, Turkey

${ }^{2}$ Department of Chest Diseases, Division of Immunology and Allergy, Erciyes University, Faculty of Medicine, Melikgazi 38039, Kayseri, Turkey

\begin{abstract}
The role of extracellular matrix in lung disease has been an area of increasing research interest. Numerous studies have demonstrated the importance of extracellular matrix in pulmonary pathologies. Evaluation of the intracellular function and basic structural properties of proteoglycan adhesion proteins and structural proteins may reveal new approaches to the treatment of pulmonary disease. This manuscript summarizes the role of extracellular matrix in pulmonary diseases based on the currently available literature.
\end{abstract}

Keywords: Extracellular matrix; Lung; diseases; Pulmonary

\section{Introduction}

Extracellular Matrix (ECM) is the biologically active connective framework extending between cells; the composition of the ECM contributes significantly to wound healing, cell proliferation, cell mobility, and cell differentiation [1]. ECM occurs in two basic forms in animal tissues: stromal matrix and basement membrane [2]. The basement membrane is a thin layer of ECM located on the basolateral epithelium and separating epithelial tissue from connective tissue. Stromal matrix is associated with connective tissue and generally located within the arterial walls as well as in fibrous tissue, tendons and skin.

Interaction with the surrounding ECM is an essential component of cellular differentiation and morphogenesis. Although ECM is well known as a structural component of tissues and organs, it has many other functions including regulation of cell morphology, cellcell interaction and signaling, and cellular differentiation [3]. The biomechanical properties of ECM, such as rigidity and deformability, can directly influence cell behavior through mechano transduction mechanisms [1].

ECM consists of several distinct components (Figure 1) which can be divided into three groups: i) structural proteins, such as collagen and elastin, ii) specialized adhesion proteins, such as fibronectin, fibrilin, and laminin, iii) glycosaminoglycans (GAG) and proteoglycans (PG). ECM components are synthesized within the cell and secreted by exocytosis [4]. Collagen (type I, III, and V on the airway wall and type IV and VIII under the basement membrane) and elastin account for approximately $2 / 3$ of the dry weight of ECM, while the remainder is made up of glycoproteins (fibronectin, tenascin, laminin) and other matrix components (heparin sulfate, hyaluronan).

ECM proteins modulate signal transduction events through interactions with a class of adhesion receptors known as integrins [5]. ECM proteins and other components play an important role in cellular differentiation, proliferation, polarization and migration [6]. Growth factors, including VEGF, IGF, FGF, TGF- $\beta$ embedded in the ECM regulate cellular distribution, proliferation, and differentiation though interactions with cell surface integrins [7]. The role of ECM proteins in pulmonary disease, particularly pulmonary arterial hypertension (PAH), has been an area of increasing research interest. For example, it has been reported that patients with PAH have increased plasma levels of the ECM GAG hyaluronan (HA) [8], and that structural modification of HA occurs in patients with PAH [9]. In this paper, we examine the role of ECM in pulmonary disease.

\section{Structural Proteins}

Collagen and elastin make up the structural ECM proteins. Collagens are a family of ECM proteins involved in wound healing, morphogenesis, chemotaxis and cell migration, cell adhesion, and tissue structure [10]. To date at least 28 types of collagen have been identified in vertebrates [11]. All isoforms of collagen are made up of a "triple helix" comprised of three independent collagen chains [12]. Collagen is secreted by fibroblasts in the stroma or adjacent tissues following post-translational modification in the Golgi apparatus and endoplasmic reticulum [13]. Elastin is a structurally important protein, allowing tissues to return to their original shape following deformation. Collagen and elastic fibers are major structural elements of the pulmonary connective tissue matrix, with different mechanical properties. The ratio of elastin to collagen is thought to determine ECM elasticity. Chronic hypoxia-induced PAH progression is correlated with collagen and elastin deposition in the arterial wall [14]. The elastic modulus of collagen fibers is greater than the elastic modulus of elastin fibers $[15,16]$. Collagen and elastin fibrils are intertwined to create a functional extracellular network in the lung, capable of generating the force required for the passive response during breathing. During pulmonary fibrosis, an increased proportion of collagen relative to elastin causes changes in tissue mechanics, particularly the loss of elastic properties, resulting in shortness of breath $[17,18]$.

\section{Adhesion Proteins}

A variety of proteins, including fibronectin, laminin, fibrilin, tenascin, vitronectin, osteonectin is involved in cellular adhesion to the ECM. Fibronectin (FN) includes several variant proteins, each

*Corresponding author: Metin Aytekin, PhD, Faculty of Medicine, Department of Medical Biology, Erciyes University, Kayseri, 38039, Turkey, Tel: 00-90-352-207 66 66/23335; Fax: 00-90-352-437 52 85; E-mail: metin.aytekin@gmail.com

Received March 12, 2014; Accepted April 16, 2014; Published April 23, 2014

Citation: Derya M, Yılmaz I, Aytekin M (2014) The Role of Extracellular Matrix in Lung Diseases. Biol Med 6: 200. doi: 10.4172/0974-8369.1000200

Copyright: ( 2014 Derya M. This is an open-access article distributed under the terms of the Creative Commons Attribution License, which permits unrestricted use, distribution, and reproduction in any medium, provided the original author and source are credited. 


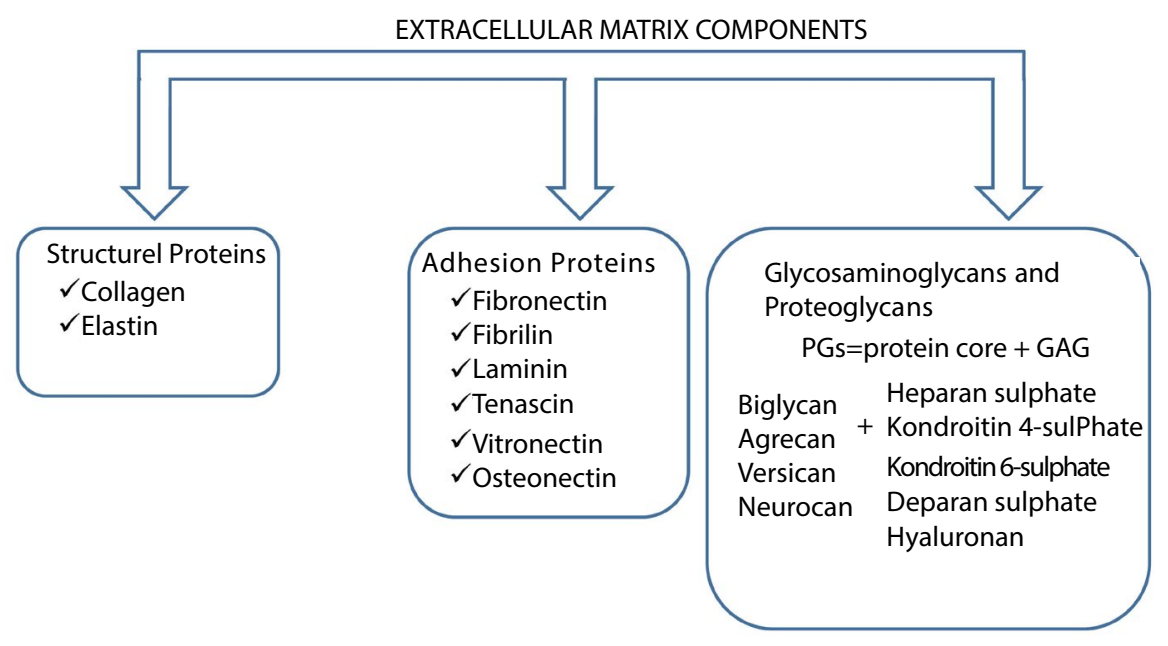

Figure 1: Demonstration of extracellular matrix components in groups. These ECM types consist of a group of three different molecular components.

produced by alternative splicing of a single gene. Each fibronectin molecule is a dimeric glycoprotein formed from two fibronectin peptides connected by disulfide bonds [19] (Figure 2), and contains binding sites for the attachment of other molecules [20]. While soluble forms are found in the blood, insoluble forms are linked by disulfide bonds to collagen fibrils in the ECM [21]. Fibronectins are known to contribute to cell adhesion, migration, growth and differentiation [22]. Laminins are major ECM proteins formed from three distinct protein chains $(\alpha, \beta, \gamma)$ [23]. They contain conserved motifs for binding to cell surface receptors and other ECM components [24]. Critical to tissue structure and cell function, laminins are important in many disease processes [25]. Numerous studies have evaluated the role of laminin in tumor invasion, metastasis, and angiogenesis, demonstrating that abnormal synthesis of laminin, alterations in chain composition, and proteolytic modification of laminin may contribute to dysregulated interactions between cancer cells and ECM [26].

\section{Glycosaminoglycans and Proteoglycans}

Proteoglycans (PG) are composed of a core protein covalently bound to linear glycosaminoglycan (GAG) carbohydrate polymer chains. Gylcosaminoglycans account for the majority of the total mass of many proteoglycans. GAGs are composed of repeating disaccharide units linked end-to end to form linear heteropolysaccharide chains (Figure 3).

PGs may be classified according to several sub-groups [27-29]. The proteoglycans aggrecan, versican, neurocan and brevican make up one such group based on their structural and functional similarities. The core proteins of aggrecan-like proteoglycans contain a hyaluronanbinding $\mathrm{N}$-terminal domain and a selectin-binding $\mathrm{C}$-terminal domain. Aggrecan-like PGs have major structural functions within tissues, although versicans have also been demonstrated to stimulate the proliferation of fibroblasts [30]. A second group includes proteoglycans containing leucine-rich repeat domains, such as decorin, biglycan, fibromodulin and kerotocan, The leucine-rich domains of these proteoglycans mediate protein-protein interactions, contributing to the organization of the collagen network. Decorin also participates in signal transduction [25].

The anionic and non-sulfated glycosaminoglycan hyaluronan (HA), is an essential component of the extracellular matrix. HA is a high molecular weight polysaccharide consisting of repeated disaccharide units, and is distinguished from the other GAGs by the absence of sulfated residues and exceptionally high molecular weight (Figure 4).

Hyaluronan is synthesized in the plasma membrane by any one of three homologous enzymes (HAS1, HAS2, HAS3) known as hyaluronan synthases [31]. Catalysis of HA occurs through the action of hyaluronidase, B-D-glucuronidase, and $\beta-\mathrm{N}$ actyl-hexoaminidase enzymes [32]. Prominent cell-surface receptors for HA are CD44 and RHAMM (Receptor for Hyaluronan-mediated motility). HA receptors participate in cellular signal transduction and have been associated with metastasis [33-36]. HA is present at high concentrations in the connective tissues such as the skin, umbilical cord, and synovial fluid [37]. Significant amounts of HA have also been reported in lung, kidney, brain, and muscle tissue [38]. A typical $70 \mathrm{~kg}$ human body will contain as much as $15 \mathrm{~g}$ HA [39]. HA contributes to cell proliferation and cell migration, and has been implicated in the progression of certain malignancies [40]. Although HA is found as high molecular weight (HMW) polymer under normal physiological conditions, low molecular weight (LMW) HA occurs during tissue injury and inflammation $[41,42]$. LMW HA has been demonstrated to induce expression of inflammatory genes including nuclear Factor kappa $\mathrm{B}$ $\left(\mathrm{NF}_{\mathrm{K}} \mathrm{B}\right)$, macrophage inflammatory protein-1a (MIP-1a) and MIP-1b $[43,44]$.

Matrix metalloproteinases (MMPs) are a family of zinc enzymes responsible for the degradation of extracellular matrix components such as elastin, collagen, proteoglycans, laminin and fibronectin during tissue remodeling processes [45]. There are 24 defined MMP enzymes. These enzymes are expressed by alveolar macrophages, neutrophils, eosinophils and airway epithelial cells [45]. They are secreted as inactive pro-enzymes in a latent form and are active in a truncated form following further proteolytic processing in the extracellular environment. MMPs are divided into subgroups, distinguished by specific structural domains: collagenases, gelatinases, stromelysins, matrilysins, metaloelastases, and membrane type matrix metalloproteinases (MT-MMPs) (Figure 5) [46].

Cytokines such as TNF- $\alpha$, IL- 1 and TGF- $\beta$ can directly modulate MMP expression and enzymatic activity [47-49]. MMP expression is 


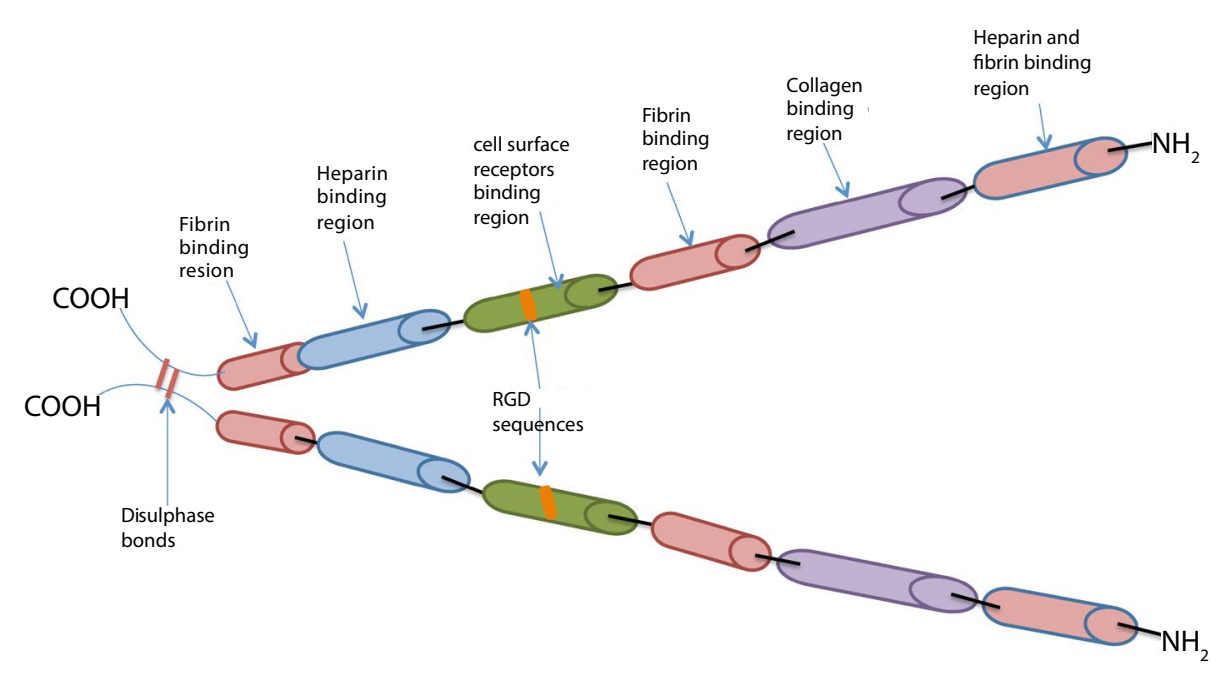

Figure 2: Fibronectin is a dimeric glycoprotein formed from two fibronectin peptides connected by disulfide bonds.

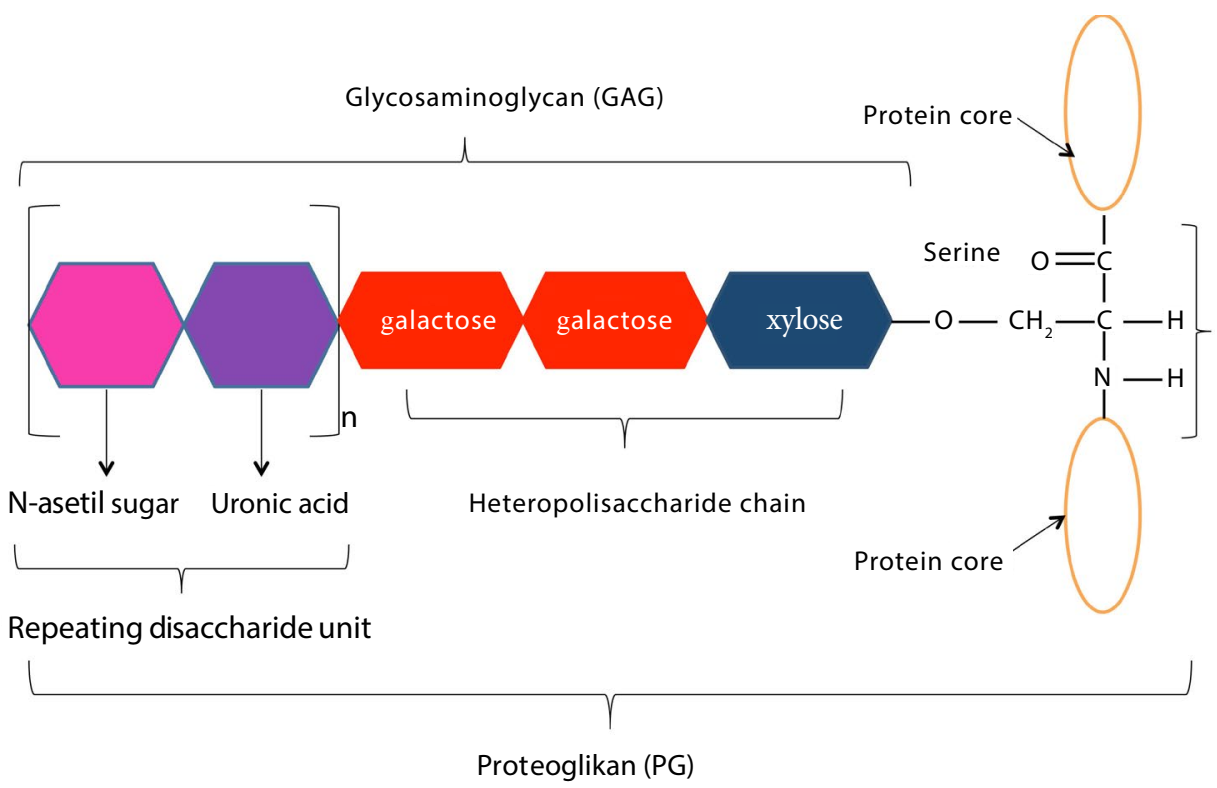

Figure 3: Glycosaminoglycans are composed of a repeating disaccharide unit and heteropolysaccharide chain.

a critical component of hormone-dependent tissue remodeling and development, and altered MMP activity contributes to pathological processes such as inflammation, tissue repair, tumor invasion and metastasis. MMP-mediated catalysis modulates the bioavailability of growth factors, cytokines and chemokines by enhancing or inhibiting specific interactions with adhesion receptors, modifying cell-cell and cell-ECM interactions [25]. Overexpression of MMP enzymes may contribute to pulmonary diseases [50-53]. Abnormal expression of MMPs and tissue matrix metalloproteinase inhibitors (DIMPs) alters the local cellular microenvironment to facilitate cancer invasion and metastasis [54].

Collectively, the individual components of the ECM shape a variety of pathological processes. In the present review, the role of ECM in the pathogenesis of pulmonary disease is discussed.

\section{Asthma and ECM}

Asthma is a global health problem that affects approximately 300 million people of all ages across the world. Two hundred fifty thousand people are estimated to die prematurely every year as a result of asthma [55]. Asthma is characterized by histopathological inflammation and tissue remodeling in the lower respiratory tract [56]. Clinical characteristics associated with severe asthma are airway obstruction, wheeze and shortness of breath, cough, nocturnal awakenings, chest tightness, atopy/allergic responses, non-steroidal anti-inflammatory reactions and airway wall thickening [57]. Changes in the function of airway smooth muscle are correlated with increased collagen and fibrillin deposition in the surrounding extracellular matrix [58].

Fibrosis and other forms of airway tissue remodeling play an important role in the loss of pulmonary function associated with asthma 


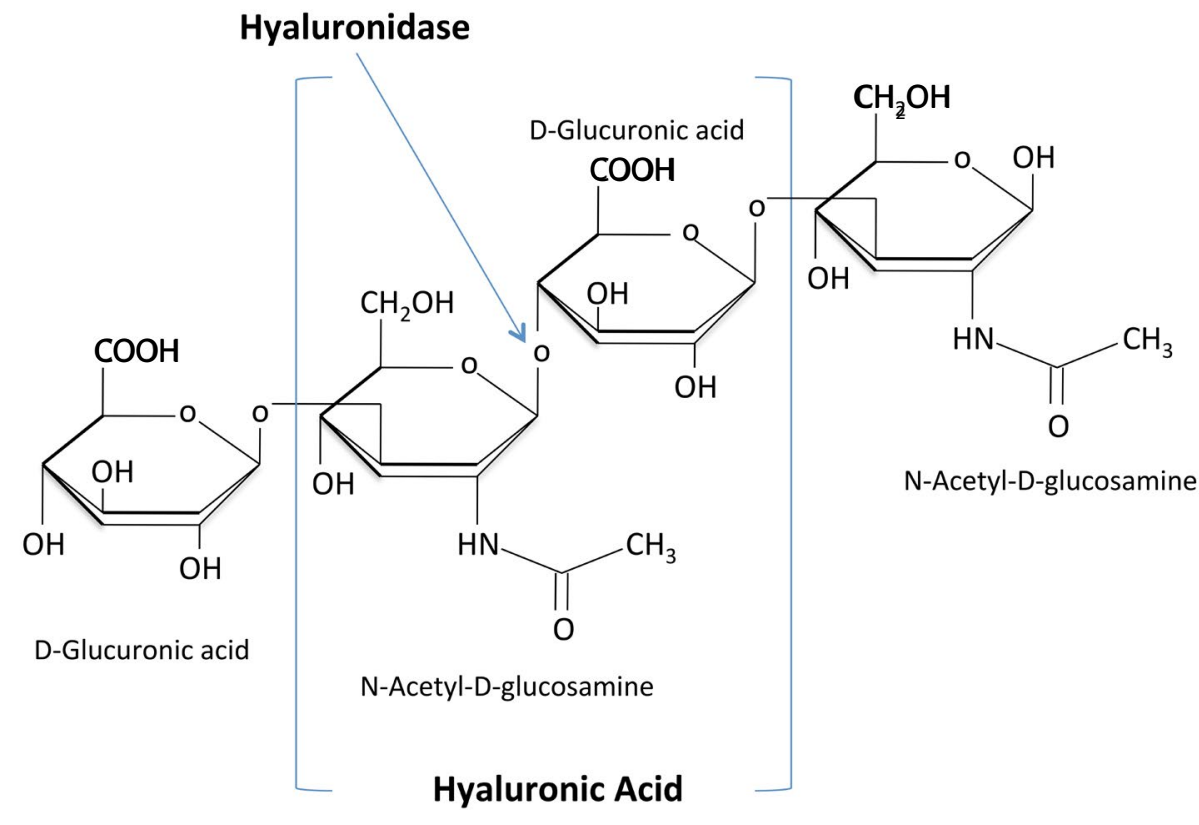

Figure 4: Hyaluronan is a high molecular weight polysaccharide consisting ofrepeated disaccharide units.

\section{(a)}

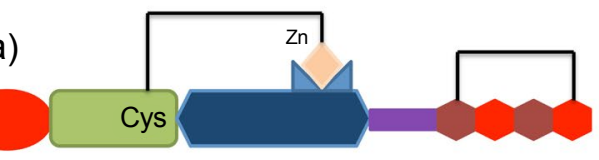

(b)

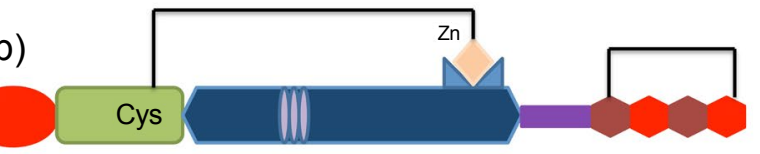

(c)
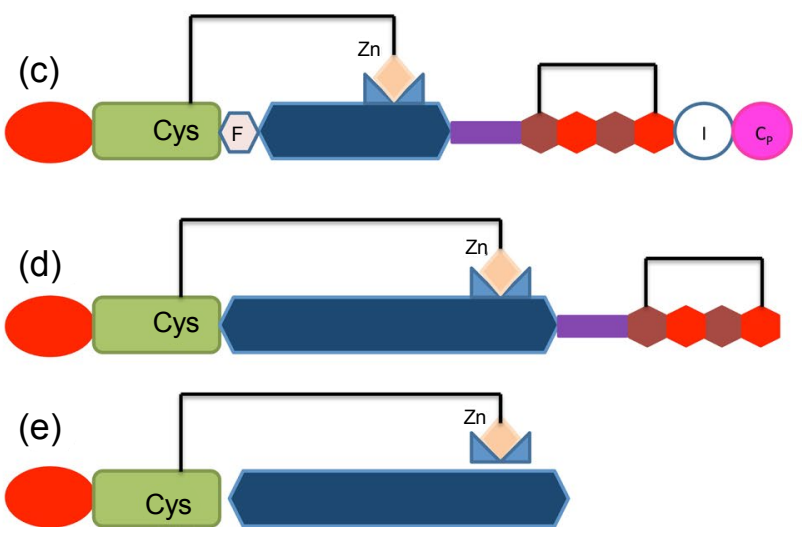

Figure 5: Matrix metalloproteinases (MMPs) is a family of zinc enzymes responsible for the degradation of extracellular matrix components. Collagenases: MMP-1,-8,-13,-18(a), Gelatinases: MMP-2,-9 (b), Transmembrane type matrix metalloproteinases (c), Stromelysins: MMP-3,-10 (d), Matrilysins; MMP-7,-26 (e).

[59]. In recent years, the contributions of inflammatory mechanisms to airway remodeling have been investigated. ECM damage and repair mechanisms also contribute to airway pathology. For example, vascular remodeling in asthma alters tissue blood flow as a result of changes in the molecular pathology of VEGF and VEGF receptor localization and expression [59].
Airway remodeling in the lower respiratory tract is associated with increased disease severity in asthma patients [60]. This includes epithelial loss, sub-epithelial fibrosis, airway smooth muscle proliferation goblet cell and mucus gland hyperplasia, angiogenesis, and airway edema. Angiogenesis in asthma is characterized by the uneven enlargement of the bronchial vascular structures and contributes to airway wall thickening [61,62]. 
One of the pathological consequences of extracellular matrix remodeling is the thickening of the basement membrane and smooth muscle hypertrophy. Basement membrane hyperplasia is strongly associated with asthma [63]. The essential components of the airway wall include type I, II, and VI collagen; type IV collagen is found in the basement membrane. In particular, accumulation of collagen type III and V, and to a lesser degree type I collagen and fibronectin in the reticular layer has been associated with asthma [64,65]. Myofibroblasts underlying the epithelium are thought to be the primary source of collagen deposition resulting in the thickening of the basement membrane [66].

MMP and DMPIs are thought to be involved in the pathogenesis of asthma, resulting in altered matrix turnover and influencing the function and distribution of inflammatory cells. While increased MMP/DMPI expression may enhance tissue damage, down-regulation of MMP/DMPI may result in fibrosis [67].

Airway smooth muscle cells (ASMCs) are influenced by the surrounding ECM. The composition of the ECM within the airway smooth muscle tissue has been evaluated by several investigators. Araujo et al. [68] evaluated the expression of major ECM components, MMPs, and tissue inhibitors in ASMCs within the lung tissue of asthmatic patients. Increased expression of MMP-9 and MMP-12 in the respiratory tract was has been associated with fetal asthma. Pulmonary disorders may be preventable through the inhibition of specific matrix proteases in cases of non-congenital asthma.

HA fragments have been demonstrated to stimulate the production of inflammatory cytokines in macrophages [69]. In a study evaluating the role of fragmented hyaluronan in asthma pathogenesis, treatment of mice with hyaluronan fragments resulted in the up-regulation of TLR (Toll-like receptor) 2 and TLR $_{4}$ in macrophages, suggesting a novel proinflammatory mechanism capable of triggering chronic inflammation and airway remodeling [70]. This result suggests that hyaluronan homeostasis is disrupted in patients with asthma, and the accumulation of hyaluronan in the lungs of asthmatic patients may be related to the activation of macrophages and fibroblasts. This previously unknown inflammatory pathway may lead to new therapeutic strategies that target macrophages, fibroblasts, and matrix turnover in patients with severe and persistent asthma.

\section{Idiopathic Pulmonary Fibrosis and ECM}

Fibrosis is a form of chronic tissue damage characterized by the pathologic accumulation of ECM components and the remodeling of pulmonary tissue. Clinical and radiological findings are used in the diagnosis of pulmonary fibrosis. Fibrosis results from the imbalance of two physiologic processes: i) the proliferation and apoptosis of fibroblasts, ii) the production and degradation of ECM components. Excessive ECM occurs as a result of an imbalance between the breakdown and synthesis of ECM components. Fibroblasts accumulate when the balance between apoptosis and proliferation is altered as a result of decreased apoptosis [71].

In cases of idiopathic pulmonary fibrosis (IPF), myofibroblasts accumulate in regions undergoing tissue remodeling, producing extracellular matrix components that alter organ function, including collagen and hyaluronan. Liang et al. [70] have reported that overexpression of hyaluronan synthase enzyme-2 (HAS2) results in severe lung fibrosis and ultimately death in mice. The suppression of HAS-2 may be a useful therapeutic target in the prevention of pulmonary fibrosis.
In a review by Fernandez and Eickelberg [72], the pro-fibrotic role of TGF- $\beta$ in the pathogenesis of IPF has been evaluated. TGF- $\beta$ is produced in the lungs by different cell types and has chemotactic and proliferative properties when activated. TGF- $\beta$ contributes to the creation of a microenvironment, which alters ECM deposition. Rock et al. [73] investigated the contribution of several cell types to pulmonary fibrosis using different techniques, such as confocal analysis of normal and fibrotic human and mouse lungs using a wide range of immune histochemical markers. They reported that there is a relationship between pericytes and pulmonary fibrosis and analysis revealed that pericyte markers increased in fibrotic regions.

A study investigating the molecular and cellular mechanisms of pulmonary fibrosis suggested that multiple mechanisms, may contribute to changes in fibroblast function, loss of alveolar epithelium, and excessive accumulation of the ECM [71]. This includes: i) inflammatory mechanisms such as altered expression of cytokines and cell surface molecules and the proliferation of immune cells, ii) oxidative stress and oxidative signaling mechanisms, and iii) coagulation disturbance including the aggregation of proteinases and their cognate receptors.

Parker et al. [74] examined the interaction between ECM and fibroblasts within the lung tissue integrity of patients with IPF, Reporting a positive feedback loop between fibroblasts and aberrant ECM in IPF and suggesting that interrupting this loop may be a novel strategy for IPF treatment.

Blaauboer et al. [75] reported that the interaction between fibroblasts and ECM composition contributes to the development of lung fibrosis. Three proteins, elastin, type $\mathrm{V}$ collagen and tenascin $\mathrm{C}$, are highly expressed in active fibrosis. Extracellular elastin leads to myofibroblast differentiation, contributing to disease progression.

Tissue fibrosis is the result of an abnormal response to organ damage and is often characterized by hyper proliferation of fibroblasts, their differentiation into myofibroblasts, and the overproduction of specific ECM components. ECM overproduction alters the biochemical and biomechanical properties of the surrounding tissue and contributes significantly to disease progression [76]. Determining the expression of specific ECM components at different stages of disease progression is an essential task in understanding the etiology of pulmonary disease. Given that fibrotic tissue damage occurs as a result of the relative concentration and distribution of specific ECM components, the targeted inhibition of ECM synthesis may be a novel therapeutic pathway in pulmonary fibrosis.

\section{Pulmonary Arterial Hypertension (PAH) and ECM}

PAH is defined as pulmonary artery pressure $\geq 25 \mathrm{mmHg}$ as assessed by right heart catheterization at rest [77]. PAH is characterized by vascular regeneration, and the slow decline in pulmonary flexibility in PAH may result in right heart failure [78]. Although the histopathology of idiopathic pulmonary hypertension (IPAH) has been studied extensively, the mechanism accounting for the destruction of the pulmonary arteries in IPAH is not fully understood $[79,80]$. While the majority of previous studies have implicated abnormalities in the vascular endothelium and smooth muscle in pulmonary artery dysfunction, degradation of the extracellular matrix has also been associated with pathological vascular regeneration [81-83]. Recently, GAGs, including hyaluronan, have been demonstrated to induce inflammation and pathologic vascular regeneration [41,84]. Elevated HA concentration has been reported in the plasma and lungs of patients with $\mathrm{PAH}[42,85]$. In a rat model of monocrolatine (MCT) 
induced pulmonary hypertension, increased enzymatic degradation of HA was associated with pulmonary hypertension progression [51]. Pro-inflammatory HA fragments enhance pathological vascular remodeling, suggesting that the prevention of HA degradation may inhibit these pathological processes. Expression of the glycoprotein tenascin- $\mathrm{C}$ is induced by MMP secretion, and subsequently mediates the induction of smooth muscle cell proliferation by growth factors in the ECM; altered tenascin-C expression has been associated with both experimental and clinical pulmonary hypertension [86].

PAH pathology includes enhanced inflammatory activity and the proliferation of immune cells. Inhibition of the generation of proinflammatory HA fragments may be an alternate treatment strategy in $\mathrm{PAH}$.

\section{Lung Cancer and ECM}

While lung cancer was a relatively rare disease at the beginning of the 20th century, disease incidence has increased alongside the expansion of tobacco use and lung cancer is now the most common form of cancer internationally. Lung cancer accounts for $12.8 \%$ of all of the cancer cases and $17.8 \%$ of cancer deaths annually $[87,88]$.

Improved treatment of lung disease requires a variety of new biomarkers [89]. Cell adhesion molecules play an important role in cancer metastasis. Hyaluronan and the cell surface HA receptor CD44 may be important markers of cancer progression. While CD44 and HA are not typically expressed by normal bronchial epithelium, overexpression of both HA and CD44 has been reported in severe bronchial dysplasia and carcinoma $[90,91]$.

HA and CD44 expression exhibit strong positive correlation in lung cancer tissues [92]. HA expression is associated with lung cancer, however the prognostic value of HA expression is dependent on the histological subtype of the cancer, such as tumor adenocarcinoma, large cell/anaplastic carcinoma, or squamous cell carcinoma [92]. Another study examined the prognostic significance of versican, the proteoglycan linking HA, collagen I, fibronectin, and laminin within the ECM [93]. Versican expression was detected within the tumor stroma, and the pattern of versican expression paralleled HA expression, suggesting that both molecules participate in the proliferation and distribution or tumor cells [93].

Small Cell Lung Cancer (SCLC) is an aggressive form of lung cancer accounting for $25 \%$ of all cases. Standard chemotherapy treatment in conjunction with radiotherapy is associated with a 5-year survival rate of 5\% [94]. Rintoul and Sethi [95] have drawn attention to the role of the ECM in the metastasis of lung cancer and the mechanisms of resistance to chemotherapeutic drugs. Intracellular fluid volume may vary greatly, despite the fact that the tumor-stroma has the same composition as the surrounding normal connective tissue. The ECM surrounding SCLC cells contains substantial amounts of fibronectin, laminin and collagen IV. Cell migration and metastasis can be prevented by inhibition of ECM degradation. However, inhibition of integrin, and thus the alteration of cell-cell and cell-ECM interactions, may prevent chemo-resistance and block tumor migration and metastasis. Alternative treatments methods may include anti-integrin therapies.

\section{ECM in COPD}

Chronic Obstructive Pulmonary Disease (COPD) is associated with significant impairment of pulmonary repair and defense mechanisms, extensive tissue damage, and both local and systemic inflammation. COPD is considered to be systemic disease [96] and DNA methylation patterns in peripheral blood cells have been linked to early diagnosis and improved disease prognosis. In a study by Qui et al. [97], both previously identified COPD genes (SERPINA ) and new candidate genes (SUT7) were linked to COPD, and DNA methylation patterns associated with COPD and low lung function were evaluated on a large scale with gene-specific resolution.

Annoni et al. [98] have reported that tobacco use alters the extracellular matrix composition in the lungs of patients with COPD. Altered or damaged ECM may result in continuous pulmonary obstruction in patients with COPD. Among COPD patients, a significant correlation between lung function and the abundance of fibronectin and elastic fibers has been reported.

Kunz et al. [99] reported that inhaled corticosteroids and smoking changes the composition of bronchial extracellular matrix components in COPD. They determined that there is an increase in versican and collagen III expression after treatment with corticosteroids. They suggested that steroids alter airway structure by increasing expression of specific ECM proteins (versican and collagen III) in COPD that are associated with improvements in lung function.

The role of ECM components such as elastin, fibronectin, and HA in COPD may be further evaluated by measuring enzyme expression and plasma concentrations of ECM components. The statistical association of changes in the expression of specific ECM components and COPD risk may suggest new treatment strategies.

Numerous studies have demonstrated the importance of ECM in pulmonary pathologies. Evaluation of the intracellular function and basic structural properties of proteoglycan adhesion proteins and structural proteins may reveal new approaches to the treatment of pulmonary disease. Examination of the specific effects of inhibition or modification of individual ECM components may reveal novel pathways in pulmonary pathobiology.

\section{References}

1. Hynes RO (2009) The extracellular matrix: not just pretty fibrils. Science 326 1216-1219.

2. Davies JA (2001) Extracellular Matrix. John Wiley and Sons, Ltd, USA.

3. Rabinovitch M (2011) Pulmonary Hypertension and the Extracellular Matrix Pulmonary Vascular Disease. JX-J Yuan, Springer Science + Business Media, USA.

4. Schultz GS, Wysocki A (2009) Interactions between extracellular matrix and growth factors in wound healing. Wound Repair Regen 17: 153-162.

5. Clause KC, Barker TH (2013) Extracellular matrix signaling in morphogenesis and repair. Curr Opin Biotechnol 24: 830-833.

6. Taipale J, Keski-Oja J (1997) Growth factors in the extracellular matrix. FASEB J 11: 51-59.

7. Ingber DE, Dike L, Hansen L, Karp S, Liley H, et al. (1994) Cellular tensegrity: exploring how mechanical changes in the cytoskeleton regulate cell growth, migration, and tissue pattern during morphogenesis. Int Rev Cytol 150: 173224

8. Kalay N, Elcik D, Canatan H, Kaya MG, Yarlioglues M, et al. (2013) Elevated plasma hyaluronan levels in pulmonary hypertension. Tohoku J Exp Med 230: 7-11.

9. Lauer ME, Aytekin M, Comhair SA, Loftis J, Tian L, et al. (2014) Modification of hyaluronan by heavy chains of inter-alpha-inhibitor in idiopathic pulmonary arterial hypertension. J Biol Chem.

10. Myllyharju J, Kivirikko KI (2004) Collagens, modifying enzymes and their mutations in humans, flies and worms. Trends Genet 20: 33-43.

11. Gordon MK, Hahn RA (2010) Collagens. Cell Tissue Res 339: 247-257. 
12. Brodsky B, Shah NK (1995) Protein motifs. 8. The triple-helix motif in proteins. FASEB J 9: 1537-1546.

13. De Wever O, Demetter P, Mareel M, Bracke M (2008) Stromal myofibroblasts are drivers of invasive cancer growth. Int J Cancer 123: 2229-2238.

14. Poiani GJ, Tozzi CA, Yohn SE, Pierce RA, Belsky SA, et al. (1990) Collagen and elastin metabolism in hypertensive pulmonary arteries of rats. Circ Res 66: 968-978

15. Sherratt MJ, Baldock C, Haston JL, Holmes DF, Jones CJ, et al. (2003) Fibrillin microfibrils are stiff reinforcing fibres in compliant tissues. J Mol Biol 332: 183193

16. Akhtar R, Schwarzer N, Sherratt MJ, Watson RE, Graham HK, et al. (2009) Nanoindentation of histological specimens: Mapping the elastic properties of soft tissues. J Mater Res 24: 638-646.

17. Rocco PR, Negri EM, Kurtz PM, Vasconcellos FP, Silva GH, et al. (2001) Lung tissue mechanics and extracellular matrix remodeling in acute lung injury. Am J Respir Crit Care Med 164: 1067-1071.

18. Suki B, Bates JH (2008) Extracellular matrix mechanics in lung parenchymal diseases. Respir Physiol Neurobiol 163: 33-43.

19. Signas C, Raucci G, Jonsson K, Lindgren PE, Anantharamaiah GM, et al. (1989) Nucleotide sequence of the gene for a fibronectin-binding protein from Staphylococcus aureus: use of this peptide sequence in the synthesis of biologically active peptides. Proc Natl Acad Sci 86: 699-703.

20. Hayashi M, Yamada KM (1983) Domain structure of the carboxyl-terminal half of human plasma fibronectin. J Biol Chem 258: 3332-3340.

21. Mosher DF (1984) Physiology of fibronectin. Annu Rev Med 35: 561-575

22. Pankov R, Yamada KM (2002) Fibronectin at a glance. J Cell Sci 115: 3861 3863.

23. Aumailley M1, El Khal A, Knöss N, Tunggal L (2003) Laminin 5 processing and its integration into the ECM. Matrix Biol 22: 49-54.

24. Timpl R, Brown JC (1994) The laminins. Matrix Biol 14: 275-281.

25. Bosman FT, Stamenkovic I (2003) Functional structure and composition of the extracellular matrix. J Pathol 200: 423-428.

26. Patarroyo M, Tryggvason K, Virtanen I (2002) Laminin isoforms in tumor invasion, angiogenesis and metastasis. Semin Cancer Biol 12: 197-207.

27. lozzo RV (1998) Matrix proteoglycans: from molecular design to cellular function. Annu Rev Biochem 67: 609-652.

28. Lander AD, Selleck SB (2000) The elusive functions of proteoglycans: in vivo veritas. J Cell Biol 148: 227-232.

29. Sugahara K, Kitagawa $H(2000)$ Recent advances in the study of the biosynthesis and functions of sulfated glycosaminoglycans. Curr Opin Struct Biol 10: 518-527.

30. Bode-Lesniewska B, Dours-Zimmermann MT, Odermatt BF, Briner J, Heitz PU, et al. (1996) Distribution of the large aggregating proteoglycan versican in adult human tissues. J Histochem Cytochem 44: 303-312.

31. Lee JY, Spicer AP (2000) Hyaluronan: a multifunctional, megaDalton, stealth molecule. Curr Opin Cell Biol 12: 581-586.

32. Csoka AB, Frost GI, Stern R (2001) The six hyaluronidase-like genes in the human and mouse genomes. Matrix Biol 20: 499-508.

33. Toole BP (1997) Hyaluronan in morphogenesis. J Intern Med 242: 35-40

34. Ahrens T, Assmann V, Fieber C, Termeer C, Herrlich P, et al. (2001) CD44 is the principal mediator of hyaluronic-acid-induced melanoma cell proliferation. $J$ Invest Dermatol 116: 93-101.

35. Noble PW (2002) Hyaluronan and its catabolic products in tissue injury and repair. Matrix Biol 21: 25-29.

36. Toole BP, Wight TN, Tammi MI (2002) Hyaluronan-cell interactions in cancer and vascular disease. J Biol Chem 277: 4593-4596.

37. Fraser JR, Laurent TC (1989) Turnover and metabolism of hyaluronan. Ciba Found Symp 143: 41-53.

38. Necas J, Bartosikova L, Brauner P, Kolar J (2008) Hyaluronic acid (hyaluronan): a review. Veterinarni Medicina 53: 397-411
39. Laurent UBG, RK Reed (1991) Turnover of Hyaluronan in the Tissues. Advanced Drug Delivery Reviews 7: 237-256

40. Delpech B, Girard N, Bertrand P, Courel MN, Chauzy C, et al. (1997) Hyaluronan: fundamental principles and applications in cancer. J Intern Med 242: 41-48.

41. Teder P, Vandivier RW, Jiang D, Liang J, Cohn L, et al. (2002) Resolution of lung inflammation by CD44. Science 296: 155-158.

42. Aytekin M, Comhair SA, de la Motte C, Bandyopadhyay SK, Farver CF, et al. (2008) High levels of hyaluronan in idiopathic pulmonary arterial hypertension. Am J Physiol Lung Cell Mol Physiol 295: L789-799.

43. Noble PW, McKee CM, Cowman M, Shin HS (1996) Hyaluronan fragments activate an NF-kappa B/l-kappa B alpha autoregulatory loop in murine macrophages. J Exp Med 183: 2373-2378.

44. Horton MR, Burdick MD, Strieter RM, Bao C, Noble PW (1998) Regulation of hyaluronan-induced chemokine gene expression by IL-10 and IFN-gamma in mouse macrophages. J Immunol 160: 3023-3030.

45. Ohbayashi $\mathrm{H}$ (2002) Matrix metalloproteinases in lung diseases. Curr Protein Pept Sci 3: 409-421.

46. Hartung HP, Kieseier BC (2000) The role of matrix metalloproteinases in autoimmune damage to the central and peripheral nervous system. Neuroimmunol 107: 140-147.

47. Edwards DR, Murphy G, Reynolds JJ, Whitham SE, Docherty AJ, et al. (1987) Transforming growth factor beta modulates the expression of collagenase and metalloproteinase inhibitor. EMBO J 6: 1899-1904.

48. Unemori EN, Hibbs MS, Amento EP (1991) Constitutive expression of a 92$\mathrm{kD}$ gelatinase (type $\mathrm{V}$ collagenase) by rheumatoid synovial fibroblasts and its induction in normal human fibroblasts by inflammatory cytokines. J Clin Invest 88: 1656-1662.

49. Lyons JG, Birkedal-HB, Pierson MC, Whitelock JM, Birkedal-HH (1993 Interleukin-1 beta and transforming growth factor-alpha/epidermal growth factor induce expression of $\mathrm{M}(\mathrm{r}) 95,000$ type IV collagenase/gelatinase and interstitial fibroblast-type collagenase by rat mucosal keratinocytes. J Biol Chem 268: 19143-19151.

50. Backstrom JR, Miller CA, Tökés ZA (1992) Characterization of neutral proteinases from Alzheimer-affected and control brain specimens: identification of calcium-dependent metalloproteinases from the hippocampus. J Neurochem 58: 983-992.

51. Opdenakker G, Van Damme J (1994) Cytokine-regulated proteases in autoimmune diseases. Immunol Today 15: 103-107.

52. Lim GP, Backstrom JR, Cullen MJ, Miller CA, Atkinson RD, et al. (1996) Matrix metalloproteinases in the neocortex and spinal cord of amyotrophic lateral sclerosis patients. J Neurochem 67: 251-259.

53. Shapiro SD, Senior RM (1999) Matrix metalloproteinases. Matrix degradation and more. Am J Respir Cell Mol Biol 20: 1100-1102.

54. MacDougall JR, Matrisian LM (1995) Contributions of tumor and stromal matrix metalloproteinases to tumor progression, invasion and metastasis. Cancer Metastasis Rev 14: 351-362.

55. Bousquet, JE Mantzouranis AA, Cruz N, Ait-Khaled CE, Baena-Cagnani, et al. (2010) Uniform definition of asthma severity, control, and exacerbations: document presented for the World Health Organization Consultation on Severe Asthma. J Allergy Clin Immunol 126: 926-938.

56. Moffatt MF (2008) Genes in asthma: new genes and new ways. Curr Opin Allergy Clin Immunol 8: 411-417.

57. Wenzel S (2012) Severe asthma: from characteristics to phenotypes to endotypes. Clin Exp Allergy 42: 650-658.

58. Chan V, Burgess JK, Ratoff JC, O'connor BJ, Greenough A, et al. (2006) Extracellular matrix regulates enhanced eotaxin expression in asthmatic airway smooth muscle cells. Am J Respir Crit Care Med 174: 379-385.

59. Postma DS, Timens W (2006) Remodeling in asthma and chronic obstructive pulmonary disease. Proc Am Thorac Soc 3: 434-439.

60. Elias JA, Zhu Z, Chupp G, Homer RJ (1999) Airway remodeling in asthma. J Clin Invest 104: 1001-1006.

61. Hoshino M, Nakamura Y, Hamid QA (2001) Gene expression of vascular 
endothelial growth factor and its receptors and angiogenesis in bronchial asthma. J Allergy Clin Immunol 107: 1034-1038.

62. Hoshino M, Takahashi M, Aoike N (2001) Expression of vascular endothelia growth factor, basic fibroblast growth factor, and angiogenin immunoreactivity in asthmatic airways and its relationship to angiogenesis. J Allergy Clin Immunol 107: 295-301.

63. Ward C, Pais M, Bish R, Reid D, Feltis B, et al. (2002) Airway inflammation basement membrane thickening and bronchial hyperresponsiveness in asthma. Thorax 57: 309-316.

64. McCarter JH, Vazquez JJ (1966) The bronchial basement membrane in asthma. Arch Pathol 82: 328-335.

65. Roche WR, Beasley R, Williams JH, Holgate ST (1989) Subepithelial fibrosis in the bronchi of asthmatics. Lancet 1: 520-524.

66. Davies DE, Wicks J, Powell RM, Puddicombe SM, Holgate ST (2003) Airway remodeling in asthma: new insights. J Allergy Clin Immunol 111: 215-225.

67. Kelly EA, Jarjour NN (2003) Role of matrix metalloproteinases in asthma. Curr Opin Pulm Med 9: 28-33.

68. Araujo BB, Dolhnikoff M, Silva LF, Elliot J, Lindeman JH, et al. (2008) Extracellular matrix components and regulators in the airway smooth muscle in asthma. Eur Respir J 32: 61-69.

69. Stern R, Asari AA, Sugahara KN (2006) Hyaluronan fragments: an informationrich system. Eur J Cell Biol 85: 699-715.

70. Liang J, Jiang D, Jung Y, Xie T, Ingram J, et al. (2011) Role of hyaluronan and hyaluronan-binding proteins in human asthma. J Allergy Clin Immunol 128: 403-411.

71. Todd NW, Luzina IG, Atamas SP (2012) Molecular and cellular mechanisms of pulmonary fibrosis. Fibrogenesis Tissue Repair 5: 11.

72. Fernandez IE, Eickelberg O (2012) The impact of TGF-|ิ ${ }^{2}$ on lung fibrosis: from targeting to biomarkers. Proc Am Thorac Soc 9: 111-116.

73. Rock JR, Barkauskas CE, Cronce MJ, Xue Y, Harris JR, et al. (2011) Multiple stromal populations contribute to pulmonary fibrosis without evidence for epithelial to mesenchymal transition. Proc Natl Acad Sci U S A 108: E14751483.

74. Parker MW, Rossi D, Peterson M, Smith K, Sikström K, et al. (2014) Fibrotic extracellular matrix activates a profibrotic positive feedback loop. J Clin Invest 124: $1622-1635$

75. Blaauboer ME, Boeijen FR, Emson CL, Turner SM, Zandieh-Doulabi B, et al (2013) Extracellular matrix proteins: A positive feedback loop in lung fibrosis? Matrix Biol.

76. Cox TR, Erler JT (2011) Remodeling and homeostasis of the extracellula matrix: implications for fibrotic diseases and cancer. Dis Model Mech 4: 165178

77. Galie N, Hoeper MM, Humbert M, Torbicki A, Vachiery JL, et al. (2009) Guidelines for the diagnosis and treatment of pulmonary hypertension: the Task Force for the Diagnosis and Treatment of Pulmonary Hypertension of the European Society of Cardiology (ESC) and the European Respiratory Society (ERS), endorsed by the International Society of Heart and Lung Transplantation (ISHLT). Eur Heart J 30: 2493-2537.

78. Ormiston ML, Slaughter GR, Deng Y, Stewart DJ, Courtman DW (2010) The enzymatic degradation of hyaluronan is associated with disease progression in experimental pulmonary hypertension. Am J Physiol Lung Cell Mol Physio 298: L148-157

79. Hassoun PM, Mouthon L, Barberà JA, Eddahibi S, Flores SC, et al. (2009) Inflammation, growth factors, and pulmonary vascular remodeling. J Am Coll Cardiol 54: S10-19.

80. Morrell NW, Adnot S, Archer SL, Dupuis J, Jones PL, et al. (2009) Cellular and molecular basis of pulmonary arterial hypertension. J Am Coll Cardiol 54 S20-31.

81. Cowan KN, Jones PL, Rabinovitch M (2000) Elastase and matrix metalloproteinase inhibitors induce regression, and tenascin- $C$ antisense prevents progression, of vascular disease. J Clin Invest 105: 21-34.
82. Vieillard-BA, Frisdal $E$, Raffestin $B$, Baker $A H$, Eddahibi S, et al (2003) Inhibition of matrix metalloproteinases by lung TIMP-1 gene transfer limits monocrotalineinduced pulmonary vascular remodeling in rats. Hum Gene Ther 14: 861-869.

83. Lepetit H, Eddahibi S, Fadel E, Frisdal E, Munaut C, et al. (2005) Smooth muscle cell matrix metalloproteinases in idiopathic pulmonary arterial hypertension. Eur Respir J 25: 834-842.

84. Cuff CA, Kothapalli D, Azonobi I, Chun S, Zhang Y, et al. (2001) The adhesion receptor CD44 promotes atherosclerosis by mediating inflammatory cell recruitment and vascular cell activation. J Clin Invest 108: 1031-1040.

85. Papakonstantinou E, Kouri FM, Karakiulakis G, Klagas I, Eickelberg O (2008) Increased hyaluronic acid content in idiopathic pulmonary arterial hypertension. Eur Respir J 32: 1504-1512.

86. Jones PL, Cowan KN, Rabinovitch M (1997) Tenascin-C, proliferation and subendothelial fibronectin in progressive pulmonary vascular disease. Am J Pathol 150: 1349-1360.

87. Parkin DM, Pisani P, Ferlay J (1999) Global cancer statistics. CA Cancer J Clin 49: 33-64, 1.

88. Spiro SG, Porter JC (2002) Lung cancer--where are we today? Current advances in staging and nonsurgical treatment. Am J Respir Crit Care Med 166: 1166-1196.

89. Wigle DA, Jurisica I, Radulovich N, Pintilie M, Rossant J, et al. (2002) Molecula profiling of non-small cell lung cancer and correlation with disease-free survival. Cancer Res 62: 3005-3008.

90. Pirinen RT, Tammi RH, Tammi MI, Pääkkö PK, Parkkinen JJ, et al. (1998) Expression of hyaluronan in normal and dysplastic bronchial epithelium and in squamous cell carcinoma of the lung. Int J Cancer 79: 251-255.

91. Suzuki H, Yamashiro K (2002) Reduced expression of CD44 v3 and v6 is related to invasion in lung adenocarcinoma. Lung Cancer 38: 137-141.

92. Pirinen R, Tammi R, Tammi M, Hirvikoski P, Parkkinen JJ, et al. (2001) Prognostic value of hyaluronan expression in non-small-cell lung cancer: Increased stromal expression indicates unfavorable outcome in patients with adenocarcinoma. Int J Cancer 95: 12-17.

93. Pirinen R, Leinonen T, Böhm J, Johansson R, Ropponen K, et al. (2005) Versican in nonsmall cell lung cancer: relation to hyaluronan, clinicopathologic factors, and prognosis. Hum Pathol 36: 44-50.

94. Hoffman PC, Mauer AM, Vokes EE (2000) Lung cancer. Lancet 355: 479-485.

95. Rintoul RC, Sethi T (2001) The role of extracellular matrix in small-cell lung cancer. Lancet Oncol 2: 437-442.

96. Gold DR, Manson JE (2012) Severe vitamin D deficiency: a prerequisite fo COPD responsiveness to vitamin D supplementation? Ann Intern Med 156 156-157.

97. Qiu W, Baccarelli A, Carey VJ, Boutaoui N, Bacherman H, et al (2012) Variable DNA methylation is associated with chronic obstructive pulmonary disease and lung function. Am J Respir Crit Care Med 185: 373-381.

98. Annoni R, Lanças T, Yukimatsu Tanigawa R, de Medeiros Matsushita M, de Morais Fernezlian S, et al. (2012) Extracellular matrix composition in COPD. Eur Respir J 40: 1362-1373.

9. Kunz LI, Strebus J, Budulac SE, Lapperre TS, Sterk PJ, et al. (2013) Inhaled steroids modulate extracellular matrix composition in bronchial biopsies of COPD patients: a randomized, controlled trial. PLoS One 8: e63430. 